\title{
Universiteit
}

Leiden

The Netherlands

\section{Hereditary thrombophilia and fetal loss: a prospective follow-up study} Vossen, C.Y.; Preston, F.E.; Conard, J.; Fontcuberta, J.; Makris, M.; Meer, F.J.M. van der; ... ; Rosendaal, F.R.

\section{Citation}

Vossen, C. Y., Preston, F. E., Conard, J., Fontcuberta, J., Makris, M., Meer, F. J. M. van der, ... Rosendaal, F. R. (2004). Hereditary thrombophilia and fetal loss: a prospective follow-up study. Journal Of Thrombosis And Haemostasis, 2(4), 592-596. Retrieved from https://hdl.handle.net/1887/5093

Version: $\quad$ Not Applicable (or Unknown)

License:

Downloaded from: https://hdl.handle.net/1887/5093

Note: To cite this publication please use the final published version (if applicable). 


\title{
Hereditary thrombophilia and fetal loss: a prospective follow-up study
}

\author{
C. Y. VOSSEN, * F. E. PRESTON, J. CONARD, J. FONTCUBERTA, M M. MAKRIS, $\$$ \\ F. J. M. VAN DER MEER, † I. PABINGER,**G. PALARETI, †† I. SCHARRER, †† J. C. SOUTO, \\ P. SVENSSON, § I. D. WALKER ฯ and F. R. ROSENDAAL * \\ *Department of Clinical Epidemiology and $†$ Hematology, Leiden University Medical Center, Leiden, the Netherlands; $\$$ Department of \\ Hematology, Royal Hallamshire Hospital, Sheffield, UK; §Department of Biological Hematology, Hôtel-Dieu Hospital, Paris, France; $\uparrow$ Department \\ of Hematology, Hospital de la Santa Creu i Sant Pau, Barcelona, Spain; **Department of Hematology and Hemostaseology, University Hospital \\ Vienna, Vienna, Austria; ††Department of Angiology and Blood Coagulation, University Hospital S. Orsola, Bologna, Italy; $\$+D e p a r t m e n t ~ o f$ \\ Internal Medicine, University Hospital, Frankfurt/Main, Germany; §§Department for Coagulation Disorders, University Hospital, Malmö, Sweden; \\ and $\uparrow$ Department of Hematology, Glasgow Royal Infirmary, Glasgow, UK
}

\begin{abstract}
To cite this article: Vossen CY, Preston FE, Conard J, Fontcuberta J, Makris M, van der Meer FJM, Pabinger I, Palareti G, Scharrer I, Souto JC, Svensson P, Walker ID, Rosendaal FR. Hereditary thrombophilia and fetal loss: a prospective follow-up study. J Thromb Haemost 2004; 2: 592-6.
\end{abstract}

\begin{abstract}
Summary. Background: As the placental vessels are dependent on the normal balance of procoagulant and anticoagulant mechanisms, inherited thrombophilia may be associated with fetal loss. Objectives: We performed a prospective study to investigate the relation between inherited thrombophilia and fetal loss, and the influence of thromboprophylaxis on pregnancy outcome. Patients andmethods: Women were enrolled in the European Prospective Cohort on Thrombophilia (EPCOT). These included women with factor (F)V Leiden or a deficiency of antithrombin, protein C or protein S. Controls were partners or acquaintances of thrombophilic individuals. A total of 191 women (131 with thrombophilia, 60 controls) had a pregnancy outcome during prospective follow-up. Risk of fetal loss and effect of thromboprophylaxis were estimated by frequency calculation and Cox regression modelling. Results: The risk of fetal loss appeared slightly increased in women with thrombophilia without a previous history of fetal loss who did not use any anticoagulants during pregnancy ( $7 / 39$ vs. $7 / 51$; relative risk $1.4 ; 95 \%$ confidence interval $0.4,4.7$ ). Per type of defect the relative risk varied only minimally from 1.4 for FV Leiden to 1.6 for antithrombin deficiency compared with control women. Prophylactic anticoagulant treatment during pregnancy in 83 women with thrombophilia differed greatly in type, dose and duration, precluding solid conclusions on the effect of throm-
\end{abstract}

Correspondence: F. R. Rosendaal, Department of Clinical Epidemiology, Leiden University Medical Center, PO Box 9600, 2300 RC Leiden, the Netherlands.

Tel.: + 3171526 4037; fax: +31 71526 6994; e-mail: f.r.rosendaal@, lumc.nl

Received 23 September 2003, accepted 9 December 2003 boprophylaxis on fetal loss. No clear benefit of anticoagulant prophylaxis was apparent. Conclusions: Women with thrombophilia appear to have an increased risk of fetal loss, although the likelihood of a positive outcome is high in both women with thrombophilia and in controls.

Keywords: fetal loss, thrombophilia, thromboprophylaxis.

\section{Introduction}

Thrombotic risk is increased in normal pregnancy, which may be the result of an evolutionary advantage associated with reduced blood loss after delivery and placenta separation. This risk is further enhanced in women with congenital or acquired thrombophilia [1]. In addition, it has been shown that postpartum blood loss is reduced in women with factor $(\mathrm{F}) \mathrm{V}$ Leiden [2,3]. As an adequate placental circulation is dependent on the normal balance of procoagulant and anticoagulant mechanisms, inherited thrombophilia may be associated with fetal loss.

In a retrospective analysis [4] of women participating in the European Prospective Cohort on Thrombophilia (EPCOT) study, we observed a slightly increased risk of fetal loss in women with hereditary thrombophilia [168/571 vs. $93 / 395$; odds ratio 1.35; 95\% confidence interval (CI) 1.10, 1.82]. Several other studies have confirmed an association between thrombophilia and fetal loss [5-18].

Subsequent to our retrospective baseline analysis [4], we followed the women in the EPCOT cohort prospectively to investigate the relation between fetal loss and inherited thrombophilia. The prospective study design allowed us to study women in a well-defined and homogeneous time frame with homogeneous general conditions, as well as to reduce 
recall bias. To prevent venous thromboembolism during pregnancy, pregnant women with inherited thrombophilia often receive thromboprophylaxis, such as heparin, oral anticoagulants or aspirin. This policy is a matter of controversy, and therefore applied in some centers, but not in all. As thromboprophylaxis could prevent fetal loss by preventing thrombosis in fetal placental vessels, we evaluated the effect of anticoagulants during pregnancy on pregnancy outcome.

\section{Subjects and methods}

\section{Subjects}

The women described in this study were enrolled in the EPCOT study between March 1994 and September 1997 and subsequently followed prospectively. The primary aim of the EPCOT study was to establish the risk of thrombosis in individuals with inherited thrombophilia. Nine centers in eight countries (Austria, France, Germany, UK, Italy, the Netherlands, Spain, and Sweden) participated and followed all consenting individuals with a deficiency of natural coagulation inhibitors (antithrombin, protein $\mathrm{C}$, protein $\mathrm{S}$ ), resistance to activated protein $\mathrm{C}$ due to $\mathrm{FV}$ Leiden, or a combination of these defects. As controls, partners or, if there were none, friends or acquaintances of the thrombophilic participants were included. Data were collected at baseline, and annually at follow-up by questionnaire, telephone or personal interview until January 2001. For follow-up data, information on the occurrence of risk situations or events was screened by questionnaire or telephone, and, when reported, further information was obtained from a physician. The data recorded at baseline included general demographic information, history with regard to thrombosis, current medication, obstetric history, family information and (only for thrombophilic individuals) details on type and subtype of thrombophilia. The data recorded at follow-up included the number of births, pregnancies and miscarriages, current medication and occurrence of risk situations for thrombosis. While there were no exclusion criteria for thrombophilic individuals, controls were excluded when they were blood relatives of an individual with an inherited thrombotic defect or were known to have heritable thrombophilia.

For assessing the risk of fetal loss, we selected from the participating women those aged between 13 and 45, with at least one pregnancy ending in livebirth or fetal loss during prospective follow-up. We excluded women with only elective pregnancy terminations. Partners of men in the cohort or female acquaintances of thrombophilic individuals were included as controls.

\section{Analysis}

Only the first pregnancy during prospective follow-up (regardless of previous pregnancies reported before inclusion) was considered for the analysis. Risk was expressed as the frequency of fetal loss, i.e. the proportion of all first pregnancies ending in fetal loss. Fetal loss was defined as any loss during pregnancy independent of time of occurrence.

In the analysis aimed at assessing the risk of fetal loss associated with thrombophilia, we excluded women who used thromboprophylaxis during their first pregnancy during prospective follow-up. The effect of anticoagulants on pregnancy outcome was analyzed by comparing the risk of fetal loss between those with anticoagulants (heparin, oral anticoagulants) during the first pregnancy and those without thromboprophylaxis during the first pregnancy since study entry. Both calculations were performed per pregnant woman (i.e. not per pregnancy) by Cox regression analysis with fetal loss as the outcome (dependent) variable and presence of thrombophilia or use of prophylaxis as covariate (independent variable). Follow-up time was the number of weeks of pregnancy. To adjust for regional effects and the influence of the number of previous pregnancies, center (as stratum) and the total number of pregnancies (as independent variable) were added in the Cox regression model. We also considered the effect of a history of fetal loss or venous thrombosis and the influence of gestation at age $\geq 35$ years.

\section{Results}

A total of 1573 women were enrolled in the cohort (988 with thrombophilia, 585 controls), of whom 191 completed at least one pregnancy during prospective follow-up (131 with thrombophilia, 60 controls). Of the controls, 37 (62\%) were female partners and $23(38 \%)$ were friends of participants with thrombophilia. Among the 131 thrombophilic women, 83 $(63 \%)$ used thromboprophylaxis during the first pregnancy in prospective follow-up. None of the controls used thromboprophylaxis during pregnancy. The main characteristics are shown in Table 1. Most women had their first fetal loss during prospective follow-up. A history of venous thrombosis was present predominantly among women with thrombophilia who used thromboprophylaxis during the first pregnancy since study entry.

\section{Fetal loss}

A total of 108 women (48 with thrombophilia, 60 controls) did not use thromboprophylaxis during the first pregnancy since study entry. Fetal loss occurred among 10 of the 48 women with thrombophilia $(21 \%)$, and among 10 of the 60 control women $(17 \%)$. The relative risk for fetal loss associated with thrombophilia was $1.4(95 \%$ CI $0.5,3.8)$, adjusted for center and the number of pregnancies. In both thrombophilic women and controls, the risk of fetal loss was higher if they had a history of fetal loss [3/9 (33\%) in both women with thrombophilia and controls] or when women were $\geq 35$ years old at gestation $[4 / 9(44 \%)$ in women with thrombophilia, 3/9 (33\%) in controls] (Table 2). A history of venous thrombosis (only present in women with thrombophilia) did not affect the risk of fetal loss. Further adjustment for a history of fetal loss and age at gestation $(<35$ vs. $\geq 35)$ resulted in a relative risk of $1.7(95 \%$ 
Table 1 Inclusion characteristics of women pregnant during prospective follow-up

\begin{tabular}{|c|c|c|c|}
\hline & \multicolumn{2}{|l|}{ Women with thrombophilia $(N=131)$} & \multirow[b]{2}{*}{ Controls $(n=60)$} \\
\hline & $\begin{array}{l}\text { First pregnancy after study } \\
\text { entry without thromboprophylaxis } \\
(N=48)\end{array}$ & $\begin{array}{l}\text { First pregnancy after study entry } \\
\text { with thromboprophylaxis } \\
(N=83)\end{array}$ & \\
\hline Age at inclusion, mean (range) & $28.7(19-41)$ & $29.1(16-39)$ & $28.7(13-38)$ \\
\hline History of pregnancies, $N(\%)^{*}$ & $30(63)$ & $48(58)$ & $34(57)$ \\
\hline History of fetal loss, $N(\%) \dagger$ & $9(19)$ & $12(14)$ & $9(15)$ \\
\hline History of VT, $N(\%)$ & $9(19)$ & $43(52)$ & $0(0)$ \\
\hline
\end{tabular}

VT, Venous thrombosis. *Range of number of pregnancies was 1-7 in women with thrombophilia and 1-5 in controls. †All women had one previous fetal loss.

Table 2 Fetal loss in women without thromboprophylaxis (heparin, oral anticoagulants, aspirin) during pregnancy

\begin{tabular}{|c|c|c|c|c|c|c|c|}
\hline & \multicolumn{6}{|c|}{ Women with thrombophilia } & \multirow[b]{2}{*}{ Controls } \\
\hline & $\begin{array}{l}\text { Single defects } \\
\text { PC }\end{array}$ & PS & AT & FVL* & $\begin{array}{l}\text { Combined } \\
\text { defects }\end{array}$ & Total & \\
\hline Pregnant, $N$ & 13 & 7 & 5 & 21 & $2 \dagger$ & 48 & 60 \\
\hline Fetal loss, $N$ & 4 & 2 & 1 & 3 & 0 & $10(21 \%)$ & $10(17 \%)$ \\
\hline History of fetal loss, $N$ & 2 & 1 & 0 & 5 & 1 & 9 & 9 \\
\hline Fetal loss, $N$ & 2 & 1 & 0 & 0 & 0 & $3(33 \%)$ & $3(33 \%)$ \\
\hline Age at pregnancy $\geq 35, N$ & 1 & 2 & 1 & 4 & 1 & 9 & 9 \\
\hline Fetal loss, $N$ & 1 & 1 & 0 & 2 & 0 & $4(44 \%)$ & $3(33 \%)$ \\
\hline
\end{tabular}

PC, Protein C deficiency; PS, protein S deficiency; AT, antithrombin deficiency; FVL, factor V Leiden mutation. * Only heterozygotes. $\dagger$ Both had protein $\mathrm{S}$ deficiency and the factor $\mathrm{V}$ Leiden mutation.

CI 0.6, 4.6) for thrombophilic women vs. controls. Exclusion of women with a history of fetal loss resulted in a relative risk of $1.4(95 \%$ CI $0.4,4.7)$ for thrombophilia carriers vs. pregnant control women, adjusted for age at pregnancy, regional effects and number of total pregnancies. Per type of defect, the relative risk, adjusted for age at gestation and number of previous pregnancies, varied little: $1.4(95 \%$ CI $0.3,5.5)$ for the $\mathrm{FV}$ Leiden mutation, $1.5(95 \%$ CI $0.2,12.9)$ for protein $\mathrm{S}$ deficiency, $1.5(95 \%$ CI $0.3,7.9)$ for protein $\mathrm{C}$ deficiency and $1.6(0.3,14.0)$ for antithrombin deficiency. Of all thrombophilic women and controls with no previous pregnancies before prospective follow-up, two of the $18(11 \%)$ thrombophilic women and five of the $26(19 \%)$ controls experienced fetal loss.

The mean number of weeks at which fetal loss took place was week 9 (range 4-18) in women with thrombophilia and week 9 (range 4-17) in controls. Eight women with thrombophilia $(80 \%)$ and nine controls $(90 \%)$ experienced a firsttrimester fetal loss (between week 0 and 12) with a relative risk for first-trimester fetal losses of $1.6(95 \%$ CI $0.5,4.7)$ adjusted for age at pregnancy, regional effects and number of total pregnancies. The frequency of caesarian sections was the same for women with thrombophilia $(21 \%)$ and control women $(20 \%)$.

For 91 of the 131 pregnant women with thrombophilia, we had information on genotyping for the prothrombin G20210A mutation. None of the 12 women with this mutation (11 heterozygous, one homozygous) experienced fetal loss. So, among a total of 14 women with combined defects, no pregnancy loss was observed.
Most of the controls were partners of men with a thrombotic defect. We assessed the effect of paternal thrombophilia on pregnancy outcome, and found none: the relative risk of fetal loss for partner controls vs. friend controls was 0.4 (95\% CI $0.1,2.2$, adjusted for center, age at gestation, number of pregnancies and history of fetal loss.

\section{Effect of using anticoagulants}

A total of 83 women with thrombophilia received thromboprophylaxis, i.e. heparin $(n=77)$, oral anticoagulants $(n=5)$ or aspirin $(n=1)$, at some point during the first pregnancy in prospective follow-up. The frequency of thromboprophylaxis varied among centers between $31 \%$ and $93 \%$ of all pregnant women with thrombophilia. The percentage of women receiving thromboprophylaxis was high for women with antithrombin deficiency or combined defects, respectively $82 \%$ and $83 \%$, compared with $61 \%$ of the women with protein C deficiency, $70 \%$ of the women with protein S deficiency, and $42 \%$ of the women with the FV Leiden mutation. The indication for thromboprophylactic treatment during pregnancy was known for 71 women $(86 \%)$, of whom only 20 women $(28 \%)$ received thromboprophylaxis to prevent fetal loss. The type, dose and duration of anticoagulant treatment therefore ranged greatly among the women with thrombophilia. Among 21 women with thrombophilia who used heparin or oral anticoagulants before week 5 of the pregnancy until the end of the pregnancy, five (24\%) experienced fetal loss with an unadjusted relative risk of fetal loss associated with thromboprophylaxis of $1.1(95 \% \mathrm{CI}$ 
0.4,3.3), and a relative risk adjusted for center, total number of pregnancies, history of fetal loss and age at gestation of 0.7 $(95 \%$ CI $0.2,3.2)$. The mean pregnancy duration until miscarriage in these women was 13 weeks (range 6-29).

\section{Discussion}

Earlier retrospective data in the EPCOT study showed that the risk of fetal loss was increased in women with thrombophilia (168/571 vs. 93/395; odds ratio 1.35 ; $95 \%$ CI $1.01,1.82)$ [4]. We found a similar risk during this prospective follow-up study of $1.4(95 \%$ CI $0.4,4.7)$ for thrombophilic women without a previous history of fetal loss and who did not use any anticoagulants during pregnancy versus controls, adjusted for age, number of previous pregnancies and regional effects. Even though the present study in itself could not exclude the absence of an increased risk with a $95 \%$ CI from 0.4 to 4.7 , this statistical uncertainty is likely to be the result of the smaller number of pregnancies compared with the retrospective analysis, and the results of both analyses are in agreement. A major difference between the prospective and retrospective analyses is that the odds ratio in the retrospective analysis was higher for stillbirth than for miscarriage, whereas none of the women experienced a stillbirth in the prospective analysis. This difference is probably the result of the lower number of individuals followed in the prospective study; $4 \%$ of the thrombophilic women experienced a stillbirth in the retrospective study and $27 \%$ a miscarriage, so if we take these percentages (which are based on a longer follow-up period), we would expect two stillbirths and 13 miscarriages in the 48 women without use of anticoagulants during prospective follow-up.

Per defect, we found similar risks of fetal loss: 1.4 (95\% CI $0.3,5.5)$ for the FV Leiden mutation, $1.5(95 \% \mathrm{CI} 0.2,12.9)$ for protein S deficiency, $1.5(95 \%$ CI $0.3,7.9)$ for protein $\mathrm{C}$ deficiency and $1.6(0.3,14.0)$ for antithrombin deficiency. Previously, we found similar odds ratios for miscarriage per type of defect: $0.9(95 \%$ CI $0.5,1.5)$ for the FV Leiden mutation, $1.2(95 \%$ CI $0.7,1.9)$ for protein $\mathrm{S}$ deficiency, 1.4 $(95 \%$ CI $0.9,2.2)$ for protein C deficiency and 1.7 (95\% CI 1.0, 2.8) for antithrombin deficiency [4].

Earlier retrospective studies reported similar [19,20] or higher $[10,15]$ risks of fetal loss in women with a deficiency of antithrombin, protein S or protein C. For FV Leiden, several previous reports showed an association with late fetal loss (2nd and 3rd trimester) [5,6,8-11,16-18], while reports were contradictory on the association with early fetal loss (1st trimester) [5,7,9,12-14,16-18,21-24]. Discrepancies between studies could be explained by their design: many previous reports were based on case-control studies targeting recurrent miscarriage without a comparison with women in the general population, which precludes risk calculation. According to Bick et al., 55-62\% of recurrent miscarriages are caused by blood coagulation protein or platelet defects, whereas about $90 \%$ of first-time miscarriages are caused by chromosomal defects [25]. In our study most women [39/48 (81\%); Table 1] had their first fetal loss during prospective follow-up. It may well be that thrombophilia plays a role in a small selected group of women with recurrent fetal loss, who are likely to have some other, as yet unknown, defects.

We found no positive effect of thromboprophylaxis on the outcome of a pregnancy in 21 women with thrombophilia who used heparin or oral anticoagulants before week 5 of pregnancy until the end of the pregnancy (relative risk $0.7 ; 95 \%$ CI 0.2, 3.2). However, this group is rather small to draw solid conclusions from and treatment in this group differed per person in type and dose, as most women received thromboprophylactic treatment during pregnancy to prevent venous thrombosis. However, since the risk of fetal loss without thromboprophylaxis was only mildly increased, a strong beneficial effect could not be expected in this study. In women with a severe thrombotic tendency and recurrent fetal loss, thromboprophylaxis may offer more benefit, although currently only non-conclusive information is available on thromboprophylaxis for pregnant women with thrombophilia and a history of obstetric complications [9,26-29].

In conclusion, although the risk of fetal loss is increased in women with thrombophilia, the overall likelihood of a positive outcome is high. Further research regarding prophylactic treatment (heparin, oral anticoagulants or newly developed anticoagulants) should be performed, targeting high-risk women, weighing risks and benefit. At the moment, thrombophylactic treatment does not seem indicated in women without a history of fetal loss for prevention of fetal loss only, while it may be a worthwhile option in women with a severe thrombotic tendency and recurrent fetal loss.

\section{Acknowledgements}

The study was supported by BIOMED II grant no BMHICT94-1565 (coordinator F.R.R.). We thank E. Briët, I. de Jonge, L. Velmans, W. Noteboom (Leiden), E. AygörenPürsün, M. Krause (Frankfurt am Main), C. Legnani (Bologna), E. Berntorp, V. Meha (Malmö), P. Bayliss (Sheffield) and S. Koder (Vienna) for their contributions to the study.

\section{Contribution of authors}

F.R.R. originated and coordinated the study together with F.E.P., I.D.W. and J.F. (the study steering committee). The first author, C.Y.V., performed the analyses and wrote the manuscript. All other authors were involved in designing the study and in collecting patient data and reviewing the manuscript.

\section{References}

1 Greer IA. Thrombosis in pregnancy: maternal and fetal issues. Lancet 1999; 353: 1258-65.

2 Lindqvist PG, Svensson PJ, Dahlbäck B, Maršál K. Factor V Q506 mutation (activated protein $\mathrm{C}$ resistance) associated with reduced intrapartum blood loss - a possible evolutionary selection mechanism. Thromb Haemost 1998; 79: 69-73. 
3 Lindqvist PG, Svensson PJ, Maršál K, Grennert L, Luterkort M, Dahlbäck B. Activated protein C resistance (FV:Q506) and pregnancy. Thromb Haemost 1999; 81: 532-7.

4 Preston FE, Rosendaal FR, Walker ID, Briët E, Berntorp E, Conard J, Fontcuberta J, Makris M, Mariani G, Noteboom W, Pabinger I, Legnani C, Scharrer I, Schulman S, van der Meer FJ. Increased fetal loss in women with heritable thrombophilia. Lancet 1996; 348: 913-6.

5 Brenner B, Mandel H, Lanir N, Younis J, Rothbart H, Ohel G, Blumenfeld Z. Activated protein $\mathrm{C}$ resistance can be associated with recurrent fetal loss. Br J Haematol 1997; 97: 551-4.

6 Brenner B, Sarig G, Weiner Z, Younis J, Blumenfeld Z, Lanir N. Thrombophilic polymorphisms are common in women with fetal loss without apparent cause. Thromb Haemost 1999; 82: 6-9.

7 Finan RR, Tamim H, Ameen G, Sharida HE, Rashid M, Almawi WY. Prevalence of factor V G1691A (factor V-Leiden) and prothrombin G20210A gene mutations in a recurrent miscarriage population. Am J Hematol 2002; 71: 300-5.

8 Foka ZJ, Lambropoulos AF, Saravelos H, Karas GB, Karavida A, Agorastos T, Zournatzi V, Makris PE, Bontis J, Kotsis A. Factor V leiden and prothrombin G20210A mutations, but not methylenetetrahydrofolate reductase C677T, are associated with recurrent miscarriages. Hum Reprod 2000; 15: 458-62.

9 Grandone E, Margaglione M, Colaizzo D, d'Addedda M, Cappucci G, Vecchione G, Sciannamé N, Pavone G, Di Minno G. Factor V Leiden is associated with repeated and recurrent unexplained fetal losses. Thromb Haemost 1997; 77: 822-4.

10 Kupferminc MJ, Eldor A, Steinman N, Many A, Bar-Am A, Jaffa A, Fair G, Lessing JB. Increased frequency of genetic thrombophilia in women with complications of pregnancy. N Engl J Med 1999; 340: 913.

11 Martinelli I, Taioli E, Cetin I, Marinoni A, Gerosa S, Villa MV, Bozzo M, Mannucci PM. Mutations in coagulation factors in women with unexplained late fetal loss. N Engl J Med 2000; 343: 1015-8.

12 Meinardi JR, Middeldorp S, de Kam PJ, Koopman MM, van Pampus EC, Hamulyák K, Prins MH, Büller HR, van der Meer J. Increased risk for fetal loss in carriers of the factor V Leiden mutation. Ann Intern Med 1999; 130: 736-9.

13 Rai R, Backos M, Elgaddal S, Shlebak A, Regan L. Factor V Leiden and recurrent miscarriage - prospective outcome of untreated pregnancies. Hum Reprod 2002; 17: 442-5.

14 Ridker PM, Miletich JP, Buring JE, Ariyo AA, Price DT, Manson JE, Hill JA. Factor V Leiden mutation as a risk factor for recurrent pregnancy loss. Ann Intern Med 1998; 128 (12 Part 1): 1000-3.

15 Sanson BJ, Friederich PW, Simioni P, Zanardi S, Huisman MV, Girolami A, ten Cate JW, Prins MH. The risk of abortion and stillbirth in antithrombin-, protein C-, and protein S-deficient women. Thromb Haemost 1996; 75: 387-8.

16 Tal J, Schliamser LM, Leibovitz Z, Ohel G, Attias D. A possible role for activated protein $\mathrm{C}$ resistance in patients with first and second trimester pregnancy failure. Hum Reprod 1999; 14: 1624-7.
17 Tormene D, Simioni P, Prandoni P, Luni S, Innella B, Sabbion P, Girolami A. The risk of fetal loss in family members of probands with factor V Leiden mutation. Thromb Haemost 1999; 82: 1237-9.

18 Younis JS, Brenner B, Ohel G, Tal J, Lanir N, Ben Ami M. Activated protein $\mathrm{C}$ resistance and factor $\mathrm{V}$ Leiden mutation can be associated with first- as well as second-trimester recurrent pregnancy loss. Am J Reprod Immunol 2000; 43: 31-5.

19 Gris JC, Quéré I, Monpeyroux F, Mercier E, Ripart-Neveu S, Tailland ML, Hoffet M, Berlan J, Daurés JP, Marès P. Case-control study of the frequency of thrombophilic disorders in couples with late foetal loss and no thrombotic antecedent - the Nimes Obstetricians and Haematologists Study5 (NOHA5). Thromb Haemost 1999; 81: $891-9$.

20 Gris JC, Ripart-Neveu S, Maugard C, Tailland ML, Brun S, Courtieu C, Biron C, Hoffet M, Hédon B, Marès P. Prospective evaluation of the prevalence of haemostasis abnormalities in unexplained primary early recurrent miscarriages. The Nimes Obstetricians and Haematologists (NOHA) Study. Thromb Haemost 1997; 77: 1096-103.

21 Dizon-Townson DS, Kinney S, Branch DW, Ward K. The factor $\mathrm{V}$ Leiden mutation is not a common cause of recurrent miscarriage. J Reprod Immunol 1997; 34: 217-23.

22 Balasch J, Reverter JC, Fábregues F, Tàssies D, Rafel M, Creus M, Vanrell JA. First-trimester repeated abortion is not associated with activated protein C resistance. Hum Reprod 1997; 12: 1094-7.

23 Kutteh WH, Park VM, Deitcher SR. Hypercoagulable state mutation analysis in white patients with early first-trimester recurrent pregnancy loss. Fertil Steril 1999; 71: 1048-53.

24 Rai R, Shlebak A, Cohen H, Backos M, Holmes Z, Marriott K, Regan L. Factor V Leiden and acquired activated protein $C$ resistance among 1000 women with recurrent miscarriage. Hum Reprod 2001; 16: 961-5.

25 Bick RL. Recurrent miscarriage syndrome and infertility caused by blood coagulation protein or platelet defects. Hematol Oncol Clin North Am 2000; 14: 1117-31.

26 Brenner B, Hoffman R, Blumenfeld Z, Weiner Z, Younis JS. Gestational outcome in thrombophilic women with recurrent pregnancy loss treated by enoxaparin. Thromb Haemost 2000; 83: 693-7.

27 Bar J, Cohen-Sacher B, Hod M, Blickstein D, Lahav J, Merlob P. Low-molecular-weight heparin for thrombophilia in pregnant women. Int J Gynaecol Obstet 2000; 69: 209-13.

28 Bar J, Mashiah R, Cohen-Sacher B, Hod M, Orvieto R, Ben-Rafael Z, Lahav J. Effect of thrombophylaxis on uterine and fetal circulation in pregnant women with a history of pregnancy complications. Thromb Res 2001; 101: 235-41.

29 Younis JS, Ohel G, Brenner B, Haddad S, Lanir N, Ben Ami M. The effect of thrombophylaxis on pregnancy outcome in patients with recurrent pregnancy loss associated with factor V Leiden mutation. Br J Obstet Gynaecol 2000; 107: 415-9. 